\title{
Integration of uncertainties in water and flood risk management
}

\author{
B. Höllermann and M. Evers \\ Department of Geography, University of Bonn, Bonn, Germany \\ Correspondence to: B. Höllermann (bhoellermann@uni-bonn.de)
}

Received: 11 March 2015 - Accepted: 11 March 2015 - Published: 11 June 2015

\begin{abstract}
Water management is challenged by hydrological and socio-economic change and hence often forced to make costly and enduring decisions under uncertainty. Thus, thinking beyond current acknowledged and known limits is important to consider these changes and the dynamic of socio-hydrological interactions. For example, reservoir management aiming at flood reduction and mitigation has to cope with many different aspects of uncertainty. The question is to what extent can, do and should these uncertainties have implications on planning and decision-making?

If practice recognises uncertainties they frequently use risk based decision approaches to acknowledge and handle them by e.g. relating them to other decision relevant factors, while science is mostly preoccupied in reducing these uncertainties. Both views are of relevance and a risk focused approach is needed to bridge the different perspectives covering all significant aspects of uncertainty. Based on a review of various characteristics and perceptions of uncertainty, this paper proposes a new analytical framework where the various aspects of uncertainty are condensed and a risk perspective is added. It thus goes beyond a pure typology and provides an overview of neuralgic points and their location and appearance during the decision-making process. Moreover this paper supports a structured and evaluated knowledge assessment and knowledge transfer for informed decision-making and points out potential fields of action and uncertainty reduction. Reservoir management targeting at flood prevention is used as an illustration to present the analytical framework, which is also amended by the needs and demands of practitioners, using first results of expert interviews.
\end{abstract}

\section{Introduction}

Reservoir management is embedded into a complex sociohydrological system sensitive to socio-economic, climate, land use and land cover changes. The multi-functionality of many reservoirs is a challenging task regarding the often opposing objectives. On the one hand water management aims at storing water for societal and ecological needs concerning energy production and compensating water shortages, while on the other hand targeting at maximizing the flood control zone for flood mitigation. Decisions are therefore made under risk and uncertainty. E.g. even though measures of mitigation have been put in place flooding may occur as precipitation turned out to be higher than anticipated from uncertain weather forecasts. Or the other way, that preventive reservoir relief in expectation of a large rain event turned out to be an overestimation increasing the risk of future supply fail- ures and economic losses. The question is to what extent can, do and should these uncertainties have implications on planning? Actors facing uncertainties also tend to compensate the uncertainty by e.g. making use of anchors (Renn, 2008). Anchors are readily available information which is sometimes put in the current context even though it may not be applicable for the exact situation. This psychological factor also stresses the need for structured uncertainty information and further poses the question: How can uncertainties be effectively integrated into decision-making in order to reduce risks or to take appropriate measures for risk mitigation?

This paper provides the basis for answering these questions by proposing a new analytical framework where various aspects of uncertainty are condensed and a risk perspective is added. Furthermore, the needs and demands of practitioners are acknowledged by using first results of expert interviews 


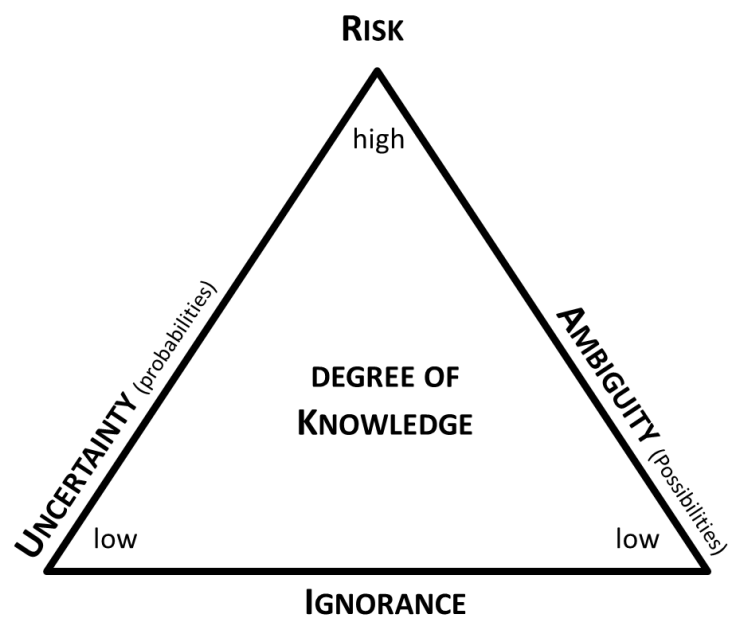

Figure 1. Uncertainty risk triangle (modified after Stirling (2010)).

amending the framework and ensuring the compatibility and operability of the framework for practitioners.

\section{Risk, uncertainty and the need for knowledge transfer}

How to distinguish between risk and uncertainty? According to the flood risk definition of the EU floods directive $2007 / 60 / \mathrm{EC}$, risk is defined as a product of the probability of occurrence of an event and its consequences, while it is not exactly known when or where the event happens. Uncertainty hereof describes the situation when occurrence probability and/or the extent of consequences are not assessable (Willows et al., 2003). With this definition risk can be regarded as an optimal state, because we command of sufficient and approved management strategies to cope with, e.g. by applying quantitative cost-benefit analysis or qualitative optimizing models. In his uncertainty matrix Stirling (2010) points out this argument by describing risk as a state of high knowledge regarding probabilities and possibilities. However, due to the unpredictability of future boundary conditions such as hydrological and ecological change, social and economic developments and especially the public awareness of e.g. flood protection measures or security needs (Hooijer et al., 2004), more and more decisions must be taken beyond the assessable risk. Decisions under complexity and uncertainty become more frequent (cf. Funtowicz and Ravetz, 1993). Stirling (2010) denotes the reduced knowledge regarding probabilities and/or possibilities as uncertainty, ambiguity, and ignorance, respectively (cf. Fig. 1). He demands that practitioners must therefore take a broader view on their degree of knowledge and their pool of decision-making methods for planning. Given this challenge an intensified information and knowledge exchange between science and policy/practice is important for key decisions. As uncertainty is part of information and not a lack of knowledge (Blöschl and Montanari,
2010) it has to be communicated and transferred as well. Therefore, integration of uncertainty information is a key criteria to choose between alternatives during a decision process (Funtowicz and Ravetz, 1993) and supports evaluation of reliability of the findings (Kinzig et al., 2003). Furthermore, it enhances transparency within the decision process (Reichert et al., 2007) and puts value on the findings by communicating their limits (Pappenberger and Beven, 2006). Given the many factors of hindrance of the science/practice dialogue (Weichselgartner and Kasperson, 2010) the question is how and what kind of uncertainty information is best presented and communicated to be effectively integrated into the decisionmaking process.

\section{Conceptualisation of the framework}

Raising trust of stakeholders and public in findings is another important reason for uncertainty assessment, however, seldom acknowledged (Maxim and van der Sluijs, 2011). While science is mostly preoccupied in reducing uncertainties, practice developed risk based approaches recognise, acknowledge and handle uncertainties by e.g. balancing them against other decision-relevant factors (Aven, 2010; Willows et al., 2003). The following sections therefore consider both perspectives: the scientific approach in uncertainty reduction and the practitioners' risk-based approach in acknowledging and handling uncertainties. By proposing an analytical framework bridging these valuable different perspectives the chapter concludes.

\subsection{Risk perspective}

Planning often relates to risk management (Smith and Stern, 2011) as it requires integrating physical and social variables as well as a variety of stakeholder interests in order to better reflect and resolve water-related trade-offs (Bakker, 2012) and/or the dynamics of the co-evolution of the sociohydrological system (Di Baldassarre et al., 2013). Here, considering uncertainties and balancing them against other concerns during the risk assessment process is important for the contextualised judgement process (Aven, 2010). Therefore, the distinction between understanding and deciding is a key concept in the risk governance framework of the international risk governance council (IRGC) reflecting the importance of first analysing all facts about the risk and then make a judgement in order to be as objective and transparent as possible (IRGC, 2005, 2008). Risk governance covers the four main steps (i) Pre-Assessment, where the risk is framed and defined considering also divers and opposing perspectives of varied stakeholder, (ii) Appraisal, where the risk is assessed using both scientific risk assessment and public perception of the risk, (iii) Characterisation and evaluation, where the risk is ranked and judged considering the scientific findings and social values, and (iv) Management, where the measure facing the risk are implemented. Communication is a cen- 


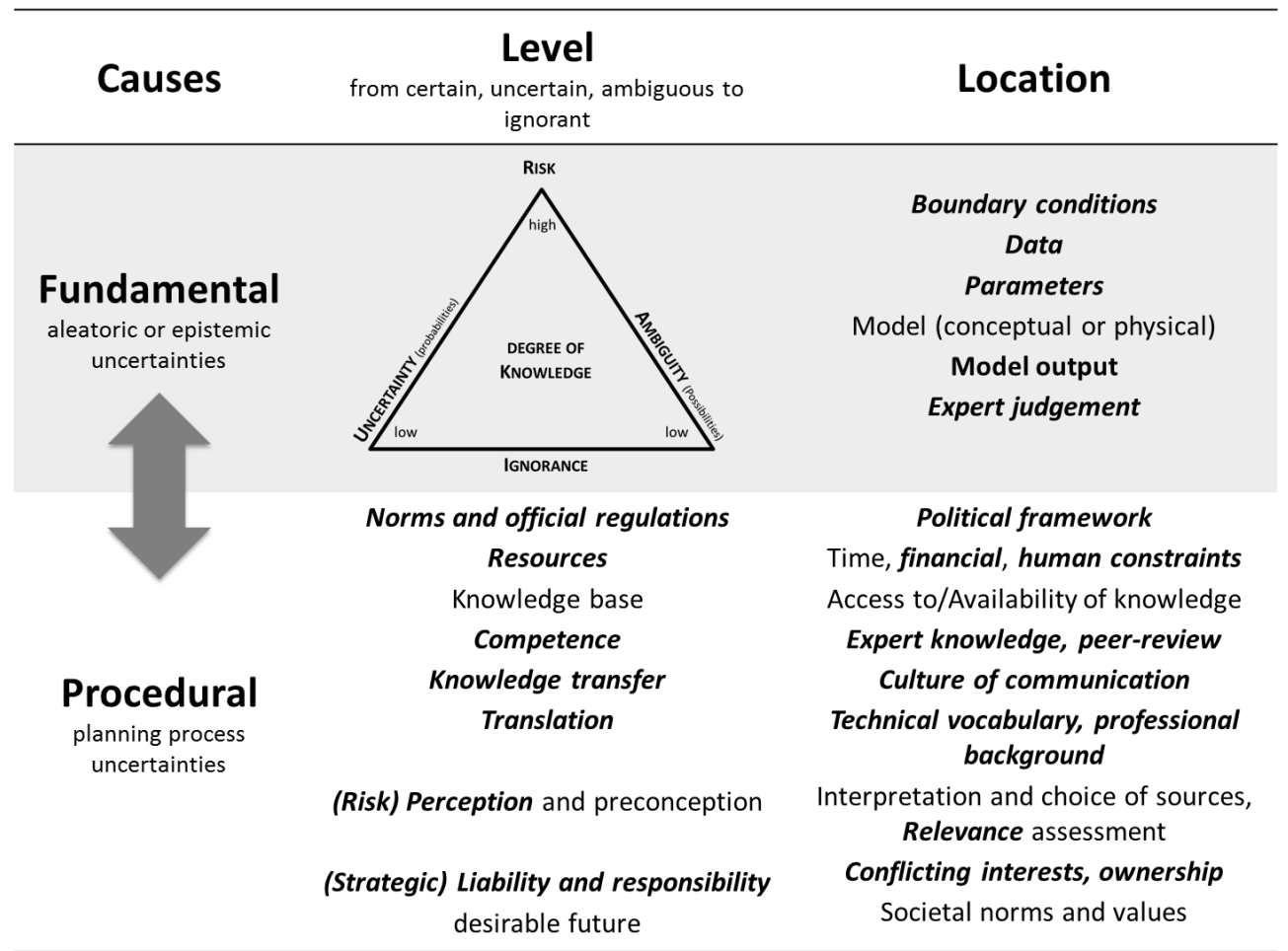

Figure 2. Condensed $2 \times 2$ uncertainty matrix (terms formatted italic bold reflect experts' uncertainty perception and experience, Sect. 4)

tral part of the risk governance framework in order to share and co-produce knowledge among the knowledge providers, actors and stakeholders along the risk governance process.

\subsection{Uncertainty perspective}

During the last 15 years multiple frameworks, typologies and characterisations of uncertainties were developed to better describe and identify uncertainty. While the approaches differ concerning their foci, perspectives and objectives, they very seldom exclude but rather overlap each other. In this chapter a selection of influential approaches, mainly in the field of water resources and related fields are presented.

Walker et al. (2003) distinguish uncertainty into level, nature and location, where level describes the degree of uncertainty, nature the causes of uncertainty and location the sources of uncertainty. Others followed this characterisation (e.g. Brugnach et al., 2007; Janssen et al., 2005; Refsgaard et al., 2007) and extended it by introducing knowledge relationships and objects (Brugnach et al., 2008) as well as the idea of cascading uncertainties (van den Hoek et al., 2014). Sigel et al. (2010) differentiate fundamental and practical causes of uncertainty as well as norm-related uncertainty, hereby adding a new uncertainty dimension. Similar, the classification of Maxim and van der Sluijs (2011) looks at three dimensions of uncertainty: substantive, contextual and procedural. Abbott (2005) acknowledges the importance of managing both environmental and planning process uncertainties.
Finally, Gabbert et al. (2010) highlight the user-driven perspective on uncertainty information needs.

How to condense and integrate the various foci, perspectives and objectives of uncertainty? First, all characterisations have an uncertainty range in common often described as the level of uncertainty. The scale ranges e.g. from "certainty" to "uncertainty" to "lack of knowledge" (Sigel et al., 2010), or from "determinism" to "statistical uncertainty, scenario uncertainty and recognised uncertainty, indeterminacy" to "total ignorance" (Walker et al., 2003). Brugnach et al. (2008) complement this "not knowing enough"-range by pointing out ambiguity as "knowing differently". van Asselt and Rotmans (2002) approach is similar with scales ranging from "inexactness" to "conflicting evidence" to "irreducible ignorance". This high overlap in the level of uncertainty can be summed up with the adapted uncertainty matrix from Stirling (2010) (Fig. 1). Second, there is broad acceptance in identifying the source or location of uncertainty, like model, input data, etc. even though some differences about the term exist (cf. Sigel et al., 2010). Third, causes of uncertainty are described by many of the authors, however, to a different extent. Walker et al. (2003) refer to the nature of uncertainty of the phenomenon, hereby distinguishing the uncertainty due to the phenomenon itself, the variability uncertainty (sometimes also called aleatoric or objective uncertainty), and the uncertainty due to the knowledge about the phenomenon (epistemic uncertainty). Notably, they focus on 


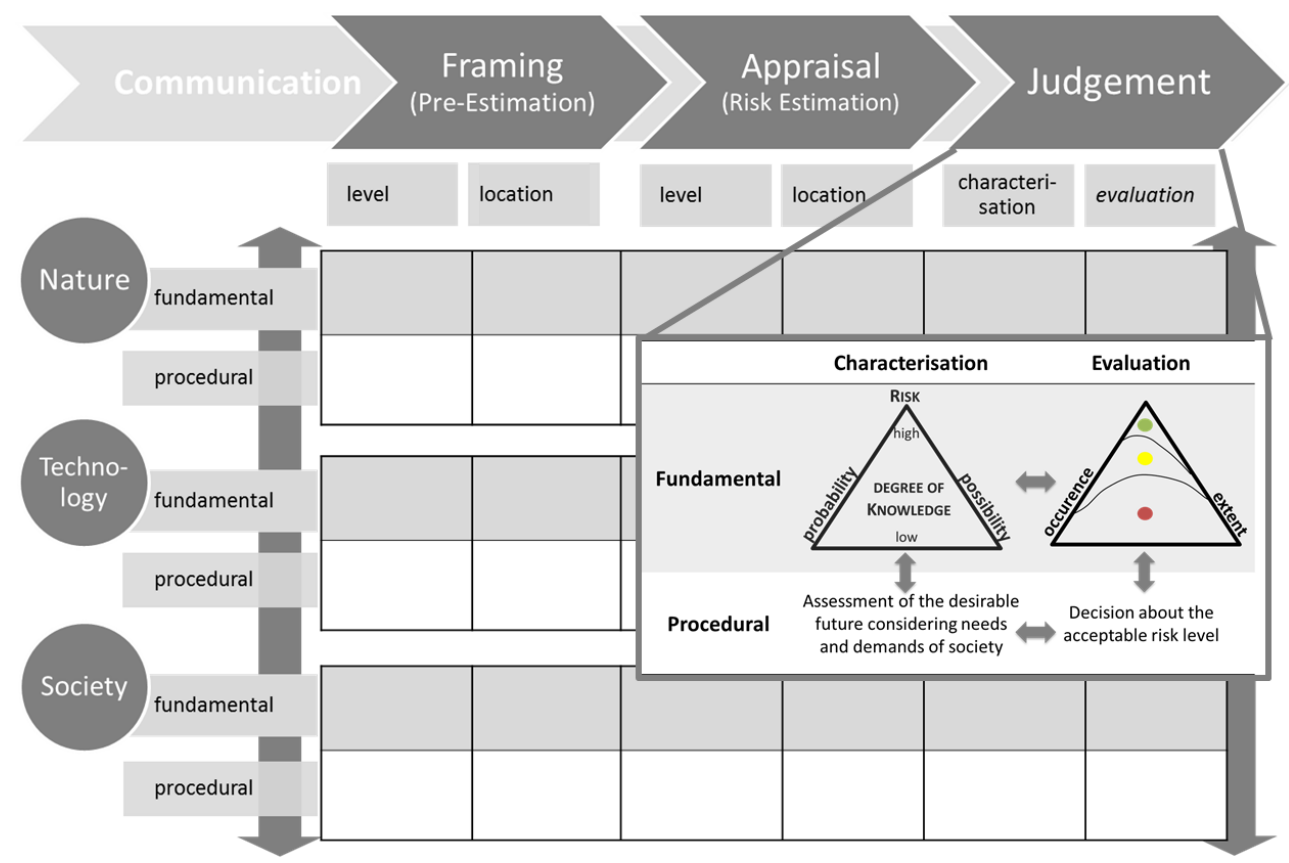

Figure 3. Analytical Framework highlighting the interrelations and mutual influence between knowledge objects and causes of uncertainty integrated into three risk governance steps. The detail box shows the special link of the uncertainty risk triangle, procedural uncertainties and the evaluation of acceptable risk levels during the judgment phase.

the causes of uncertainty of the phenomenon or - as other authors call it - the environmental, substantive or fundamental uncertainty (e.g. Abbott, 2005; Maxim and van der Sluijs, 2011; Sigel et al., 2010). In addition, uncertainty caused by planning is called process uncertainty (Abbott, 2005), procedural uncertainty (Maxim and van der Sluijs, 2011), or practical uncertainty (Sigel et al., 2010).

Conclusively, key criteria to evaluate the characteristics of uncertainty are the level and the location of uncertainty complemented by the two causes of uncertainty (Fig. 2). The level is described by using the interrelations of risk, uncertainty, ambiguity and ignorance as a degree of knowledge. This is also the case for the procedural uncertainties which occupy a central role in this matrix. While one can distinguish these two causes of uncertainty quite well, they also mutually influence each other. Improving or reducing either one may have a positive effect on the other. This effect is described by van den Hoek et al. (2014) cascades of interrelated uncertainties regarding the three knowledge objects nature, technology and society. The $2 \times 2$ matrix shows this in a clear and concise format, hereby providing a condensed yet comprehensive analytical tool to structure uncertainty information (Fig. 2). For further comprehension the completed matrix provides explanation of localisations of potential causes of uncertainty.

\subsection{Bridging the two perspectives}

The brief literature review on uncertainties shows that a vast understanding of uncertainties exists, however, so far an ex- plicit link to risk based planning and decision-making is missing. It is important to notice that during the risk governance phase the extent and emphasis of uncertainties differ, the $2 \times 2$ uncertainty matrix is therefore relevant for each step. Additionally, recognising the three knowledge objects is important to precisely identify neuralgic points, potential fields of action and interrelations (Fig. 3). Communication, illustrated by the arrow linking the different risk governance steps, is the connecting element. While the last step "risk management" is missing in this figure - as the implementation uncertainties are out of scope of this paper - the analytical framework can integrate this aspect if needed.

The challenge during the judgement process is to relate the condensed uncertainty characteristics from the two preceding phases to the evaluation of the acceptable and tolerable risk. The detail in Fig. 3 shows this reciprocal process. The traffic light model, defining limits between acceptable risk (green), necessary risk reduction measures (yellow) and intolerable risk (red) (cf. IRGC, 2005), is adjusted to a triangle, resembling the uncertainty risk triangle. Even though the two axis probabilities/possibilities and occurrence probability/extent of consequences are not of equal value and a direct comparison is not possible, the triangle illustration supports the judgement process by providing a simple tool of acknowledging and integrating uncertainty information into the evaluation process. The integration of procedural uncertainty also reflects the significance of recognising these un- 
Level

\begin{tabular}{|c|c|c|c|c|}
\hline \multirow{5}{*}{ 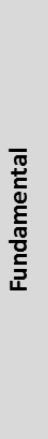 } & Uncertainty & $\begin{array}{l}\text { ensemble ranges }(A, C) \\
\text { sensitivity }(A, B, C)\end{array}$ & $\begin{array}{l}\text { Boundary } \\
\text { conditions }\end{array}$ & $\begin{array}{l}\text { actual reservoir storage volume } \\
(\mathrm{A}, \mathrm{B})\end{array}$ \\
\hline & Ambiguity & quality of model (C) & Data & $\begin{array}{l}\text { short-term weather forecast }(A) \\
\text { continous time-series data }(A, C, B) \\
\text { climate scenarios }(C) \\
\text { socio-demographic development(C) }\end{array}$ \\
\hline & (Recognised) & chaotic flood behavior (A) & Model output & robustness $(A, B, C)$ \\
\hline & Ignorance & change to risk society $(B, C)$ & Parameter & sensitivity $(A, B)$ \\
\hline & & & $\begin{array}{l}\text { Expert } \\
\text { judgement }\end{array}$ & $\begin{array}{l}\text { about robustness } \\
\text { of data, model output and } \\
\text { parameter (A) }\end{array}$ \\
\hline \multirow{6}{*}{ 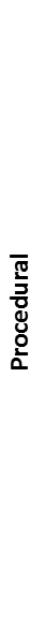 } & $\begin{array}{l}\text { Norms and } \\
\text { regulations }\end{array}$ & $\begin{array}{l}\text { permanent water retention } \\
\text { currently not approvable (C) }\end{array}$ & $\begin{array}{l}\text { Political } \\
\text { framework }\end{array}$ & $\begin{array}{l}\text { risk perception and experiences } \\
(A, C)\end{array}$ \\
\hline & Resources & $\begin{array}{l}\text { maintenance of sufficient } \\
\text { gauging stations }(A, B, C)\end{array}$ & $\begin{array}{l}\text { Financial and } \\
\text { human } \\
\text { contraints }\end{array}$ & $\begin{array}{l}\text { basis for better equipments with } \\
\text { resources: gauging stations and } \\
\text { maintenance staff (B) }\end{array}$ \\
\hline & Competence & broaden team (A) & Peer-review & consult authority $(A, B)$ \\
\hline & $\begin{array}{l}\text { Knowledge } \\
\text { transfer }\end{array}$ & $\begin{array}{l}\text { regular team meetings, } \\
\text { personal contact, public } \\
\text { communication }(A, B)\end{array}$ & $\begin{array}{l}\text { Culture of } \\
\text { communi- } \\
\text { cation }\end{array}$ & $\begin{array}{l}\text { media integration }(A) \\
\text { paradigm change to risk society } \\
(A, C)\end{array}$ \\
\hline & $\begin{array}{l}\text { Risk } \\
\text { perception }\end{array}$ & $\begin{array}{l}\text { depends on boundary } \\
\text { condition, e.g. reservoir } \\
\text { volume }(A, B)\end{array}$ & Relevance & $\begin{array}{l}\text { over sensitization against flood risk } \\
\text { (A) } \\
\text { experiences }(A, C)\end{array}$ \\
\hline & $\begin{array}{l}\text { Strategic } \\
\text { liability and } \\
\text { responsibility }\end{array}$ & $\begin{array}{l}\text { operation needs decision on } \\
\text { one value, not a range }(A) \\
\text { security factors and } \\
\text { economic viability }(B, C)\end{array}$ & $\begin{array}{l}\text { Conflicting } \\
\text { interests and } \\
\text { ownership }\end{array}$ & $\begin{array}{l}\text { potential flood mitigation versus } \\
\text { actual economic losses of } \\
\text { stakeholders (A) }\end{array}$ \\
\hline
\end{tabular}

Location

Figure 4. Flood risk management exemplified in the $2 \times 2$ uncertainty matrix. (a): operational flood management. (b): medium-term operation. (c): long-term adaptation management; accentuations in black and red bold refer to examples explained in text.

certainties as they are crucial in defining and negotiating the acceptable risk level.

Thus, the framework goes beyond a pure uncertainty characterisation by identifying information needs during the decision-making process. Moreover it points out fields of action and uncertainty reduction in respect to causes, locations and knowledge objects, hereby supporting risk evaluation under uncertainty and enhancing informed decision-making.

\section{Concept validation with expert interviews}

Aiming at understanding the needs of practitioners concerning their uncertainty management 9 experts were consulted and interviewed so far. The experts are working in German scientific state authorities and water associations with a background and profession in geoscience or engineering in water and flood risk management. The interview partners were either directly engaged in planning and decision-making processes or provided fundamentals for decision-makers. The interviews followed a semi-structured guideline covering the topics awareness and handling of uncertainty, knowledge transfer, role of uncertainties in decision and planning pro- cesses, and risk management. More interviews are envisaged and will also address experts from business focussing on e.g. hydro-power generation. The findings are first results of this ongoing research.

\subsection{Integrating the risk perspective}

All practitioners regard uncertainties as part of their daily business and have developed strategies to cope - sometimes unwittingly - with many facets of uncertainty (Fig. 4). They see uncertainty information as an important part of the information from which to assess the risk or the consequences of decisions. Hereby the interrelation of uncertainty, risk and risk perception is highlighted. Yet, few of the interviewees apply classical risk assessment explicitly. Even though at the moment, there is no explicit risk assessment, the proposed structure supports the planning process by visualising the interrelation and dependency of uncertainty and risk, hereby, providing scientifically sound and situation-adapted anchors for decision-making. Hence, the integration of a risk perspective is of high value regarding the experts' implicit risk assessment and the impact of risk perception. 


\subsection{Uncertainty focus}

Regarding the experts' uncertainty awareness, the focus on uncertainties related to operational flood management is more prominent than long-term adaptation management (Fig. 4). Analysis suggests that risks from long-term changes are perceived minor to short-term flood risk, partially as the adaptation capacity of water management is assessed high by the experts. Besides, some interviewees argued that the impact compared to the assessed long-term risk and large range of uncertainty is not high enough to account for investing in adaptation measures now. Proportionality is a key decision criterion for them.

\subsection{Interrelations of causal uncertainties}

Water managers experience trade-off situations concerning their reservoir operation in order to minimize potential flood risk damage while at once assessing the economic loss for e.g. hydro-power generation. Figure 4 highlights two examples where uncertainties influence the scope of action.

In the first example (black bold), the fundamental cause of uncertainty regarding the level of sensitivity is located in parameter sensitivity and/or actual reservoir storage volume. This boundary condition and its sensitivity may decide about the risk perception. The scope of action is then assessed by also considering the strategic responsibility for the stakeholders or customers and their economic viability. E.g. experts have to evaluate if the flood control zone is still large enough to mitigate the expected flood event without increase reservoir discharge higher than exploitable by hydro-power. The knowledge about the level of uncertainty regarding sensitivity is focal for this decision.

The second example (red bold) starts with level of uncertainty due to ensemble ranges in short-term weather forecasts. Here procedural uncertainty arises concerning competence. By e.g. improving the understanding of the climate model output robustness due to integration of peer review the level of competence increases. Some experts stressed the importance of having local, good and personal contact to climate experts. The scope of action regarding the level of preventive - potentially harmful - reservoir relief is, hence, supported by the experts' judgement of model output robustness.

\subsection{Resources and transparency}

Reflection on uncertainty handling the experts often referred to lacking resources. For flood risk management they point out the importance of monitoring data for reducing uncertainties, however, a lack of financial and human resources do not allow maintaining a large net of gauging stations. Simultaneously existing measurement nets are under pressure due to cutbacks. From the interviewees' perspective, highlighting the locations of uncertainties provides a sound base when discussing with sponsors.
Being transparent how recommendations or decisions are concluded (e.g. choice of model) is one strategy of the experts to cope with uncertainties. However, the transparency pointed out by the experts only focusses on the fundamental causes of uncertainty and neglected the process uncertainty with which they dealt unwittingly or only implicitly.

Hence, the proposed structure adds transparency to the planning process by raising awareness of the many sources of process uncertainties, the interrelations and fields of action.

\section{Conclusions and outlook}

Uncertainty matters for practitioners. They show high interest and engagement in this topic and regard uncertainty information as a complementary yet essential part in planning and decision-making. The interviewees have developed strategies to cope with and compensate uncertainties either indirectly by considering fundamental uncertainties (e.g. application of sensitivity analysis) or planning process uncertainties (e.g. increasing competence). To adequately consider the efforts and costs of assessing or reducing uncertainty and the potential impact of uncertainty with limited resources, most experts implicitly apply a - more or less unstructured - risk based planning or decision-making approach.

In addition, as Faulkner et al. (2007) propose, there is a need for translation to overcome linguistic uncertainty. During the interviews it became apparent that experts dispose of differentiated knowledge about uncertainties, however, the terms used differed from scientific terms. Participatory processes acting as knowledge brokers between science and practice are a potential solution to bridge different perceptions and conceptions in order to cope with uncertainties in flood risk management (cf. Brugnach et al., 2007). Due to limited financial, human and time resources participatory processes are not always feasible. The proposed analytical framework provides a shortcut for transferring and exchanging uncertainty information. Furthermore, the framework can also be used to support and structure participatory processes.

The consistent integration of uncertainties in flood risk management is in need of structured and condensed information. Such a structured framework will positively influence the practitioners' anchors by providing sound uncertainty information and/or making missing information visible. Moreover, it can support the practitioners in assessing the risk and potential scope of action. The presented results validated the general applicability of the framework. Ongoing expert interviews and analysis will assess the user-driven information needs more comprehensively. Nevertheless, the proposed analytical framework already bridges the two perspectives of science and practice and can therefore provide an overview of neuralgic points of uncertainty during the risk based decision-making process. It is assumed that this positively supports the choice of risk management strategies and decisions. 
Author contributions. B. Höllermann designed, carried out and analysed the expert interviews and the theoretical background. M. Evers supported the research and its design. B. Höllermann prepared the manuscript with contributions from the co-author.

Acknowledgements. The authors thank the interview partners for their support, discussion contributions and valuable insights into their uncertainty management.

\section{References}

Abbott, J.: Understanding and managing the unknown: The nature of uncertainty in planning, J. Plan. Educ. Res., 24, 237-251, 2005

Aven, T.: Misconceptions of risk, Wiley, Chichester, UK, 252 pp., 2010.

Bakker, K.: Water Security: Research Challenges and Opportunities, Science, 337, 914-915, 2012.

Blöschl, G. and Montanari, A.: Climate change impacts-throwing the dice?, Hydrol. Process., 24, 374-381, 2010.

Brugnach, M., Tagg, A., Keil, F., and de Lange, W. J.: Uncertainty matters: Computer models at the science-policy interface, Water Resour. Manag., 21, 2007.

Brugnach, M., Dewulf, A., Pahl-Wostl, C., and Taillieu, T.: Toward a Relational Concept of Uncertainty: about Knowing Too Little, Knowing Too Differently, and Accepting Not to Know, Ecol. Soc., 13, 30, available at: http://www.ecologyandsociety. org/vol13/iss2/art30/, 2008.

Di Baldassarre, G., Viglione, A., Carr, G., Kuil, L., Salinas, J. L., and Blöschl, G.: Socio-hydrology: conceptualising humanflood interactions, Hydrol. Earth Syst. Sci., 17, 3295-3303, doi:10.5194/hess-17-3295-2013, 2013.

Faulkner, H., Parker, D., Green, C., and Beven, K.: Developing a translational discourse to communicate uncertainty in flood risk between science and the practitioner, Ambio, 36, 692-703, 2007.

Funtowicz, S. O. and Ravetz, J. R.: Science for the Post-Normal Age, Futures, 25, 739-755, 1993.

Gabbert, S., van Ittersum, M., Kroeze, C., Stalpers, S., Ewert, F., and Olsson, J. A.: Uncertainty analysis in integrated assessment: the users' perspective, Reg. Environ. Change, 2010.

Hooijer, A., Klijn, F., Pedroli, G. B. M., and Van Os, A. G.: Towards sustainable flood risk management in the Rhine and Meuse river basins: Synopsis of the findings of IRMA-SPONGE, River Res. Appl., 20, 343-357, 2004.

IRGC: Risk Governance - Towards an Integrative Approach, IRGC White Paper, Geneva, 157 pp., 2005.

IRGC: An introduction to the IRGC Risk Governance Framework, Geneva, 24 pp., 2008.
Janssen, P. H. M., Petersen, A. C., van der Sluijs, J. P., Risbey, J. S., and Ravetz, J. R.: A guidance for assessing and communicating uncertainties, Water Sci. Technol., 52, 125-131, 2005.

Kinzig, A., Starrett, D., Arrow, K., Aniyar, S., Bolin, B., Dasgupta, P., Ehrlich, P., Folke, C., Hanemann, M., Heal, G., Hoel, M., Jansson, A., Jansson, B.-O., Kautsky, N., Levin, S., Lubchenco, J., Mäler, K.-G., Pacala, S. W., Schneider, S. H., Siniscalco, D., and Walker, B.: Coping with uncertainty: a call for a new sciencepolicy forum, Ambio, 32, 330-335, 2003.

Maxim, L. and van der Sluijs, J. P.: Quality in environmental science for policy: Assessing uncertainty as a component of policy analysis, Environ. Sci. Policy, 14, 482-492, 2011.

Pappenberger, F. and Beven, K. J.: Ignorance is bliss: Or seven reasons not to use uncertainty analysis, Water Resour. Res., 42, W05302, doi:10.1029/2005WR004820, 2006.

Refsgaard, J. C., van der Sluijs, J. P., Højberg, A. L., and Vanrolleghem, P. A.: Uncertainty in the environmental modelling process - A framework and guidance, Environ. Model. Softw., 22, 1543-1556, 2007.

Reichert, P., Borsuk, M., Hostmann, M., Schweizer, S., Sporri, C., Tockner, K., and Truffer, B.: Concepts of decision support for river rehabilitation, Environ. Model. Softw., 22, 188-201, 2007.

Renn, O.: Risk governance: coping with uncertainty in a complex world, Earthscan, London, 455 pp., 2008.

Sigel, K., Klauer, B., and Pahl-Wostl, C.: Conceptualising uncertainty in environmental decision-making: The example of the EU water framework directive, Ecol. Econ., 69, 502-510, 2010.

Smith, L. A. and Stern, N.: Uncertainty in science and its role in climate policy, Philos. Trans. A Math. Phys. Eng. Sci., 369, 48184841, doi:10.1098/rsta.2011.0149, 2011.

Stirling, A.: Keep it complex, Nature, 468, 1029-1031, 2010.

van Asselt, M. B., and Rotmans, J.: Uncertainty in integrated assessment modelling - from positivism to plurality, Clim. Change, 54, 75-105, 2002.

van den Hoek, R. E., Brugnach, M., Mulder, J. P. M., and Hoekstra, A. Y.: Analysing the cascades of uncertainty in flood defence projects: How "not knowing enough" is related to "knowing differently", Global Environ Chang, 24, 373-388, 2014.

Walker, W. E., Harremoës, P., Rotmans, J., van der Sluijs, J. P., van Asselt, M. B., Janssen, P., and Krayer von Krauss, M. P.: Defining uncertainty: a conceptual basis for uncertainty management in model-based decision support, Int. Assess., 4, 5-17, 2003.

Weichselgartner, J. and Kasperson, R.: Barriers in the sciencepolicy-practice interface: Toward a knowledge-action-system in global environmental change research, Global Environ. Change, 20, 266-277, 2010.

Willows, R., Reynard, N., Meadowcroft, I., and Connell, R.: Climate adaptation: Risk, uncertainty and decision-making. UKCIP Technical Report, UK Climate Impacts Programme, Oxford, 4188,2003 